\title{
Alterações bucais em pacientes submetidos a tratamento quimioterápico
}

\author{
Oral changes in patients submitted to chemotherapy treatment \\ Cambios orales en pacientes sometidos a tratamiento de quimioterapia
}

Recebido: 27/05/2021 | Revisado: 31/05/2021 | Aceito: 01/06/2021 | Publicado: 03/06/2021

\author{
Francielly Karla Vieira da Silva \\ ORCID: https://orcid.org/0000-0003-3827-750X \\ Universidade Paulista, Brasil \\ E-mail: Franciellykarla@icloud.com \\ Keven de Assis Fursel \\ ORCID: https://orcid.org/0000-0003-1121-7910 \\ Universidade Paulista, Brasil \\ E-mail: kevenfursel@hotmail.com \\ José Lopes de Oliveira Neto \\ ORCID: https://orcid.org/0000-0001-8181-6930 \\ Universidade Paulista, Brasil \\ E-mail: neto.lopes@hotmail.com \\ Myllena Isabel Bueno Villas Boas \\ ORCID: https://orcid.org/0000-0001-5450-8756 \\ Universidade Paulista, Brasil \\ E-mail: dramyllenavilasboas@gmail.com \\ Claudio Maranhão Pereira \\ ORCID: https://orcid.org/0000-0001-5511-0387 \\ Universidade Paulista, Brasil \\ E-mail: claudiomaranhao@hotmail.com
}

\begin{abstract}
Resumo
O tratamento oncológico quimioterápico invariavelmente é responsável por desencadear alterações bucais advindas da diminuição da resposta imunológica do paciente. A quimioterapia é uma das mais utilizadas e eficazes formas de tratamento oncológico, contudo desencadeia inúmeros efeitos colaterais em todos os sistemas orgânicos, inclusive em cavidade bucal. Dentre eles destaca-se a mucosite, uma das causas de maior desconforto para o paciente, responsável também por uma instabilidade em sua qualidade de vida. É essencial que o paciente com câncer procure um cirurgião dentista para que haja uma prevenção, tratamento e acompanhamento destas alterações objetivando uma melhora na qualidade de vida antes, durante e após quimioterapia ou qualquer outro tratamento oncológico. Com isso é de suma importância determinar as principais alterações bucais relacionadas ao tratamento quimioterápico, assim como avaliar a prevalência de cada alteração e seus efeitos tóxicos.
\end{abstract}

Palavras-chave: Quimioterapia; Alterações bucais; Câncer; Efeitos tóxicos.

\begin{abstract}
Chemotherapy cancer treatment is invariably responsible for triggering oral changes resulting from the decrease in the patient's immune response. Chemotherapy is one of the most used and effective forms of cancer treatment, however it triggers countless side effects in all organic systems, including in the oral cavity. Among them, mucositis stands out, one of the causes of greatest discomfort for the patient, also responsible for an instability in his quality of life. It is essential that the cancer patient seek a dental surgeon so that there is a prevention, treatment and monitoring of these changes aiming at an improvement in the quality of life before, during and after chemotherapy or any other cancer treatment. Therefore, it is extremely important to determine the main oral changes related to chemotherapy treatment, as well as to assess the prevalence of each change and its toxic effects.
\end{abstract}

Keywords: Chemotherapy; Oral changes; Cancer; Toxic effects.

\section{Resumen}

Chemotherapy cancer treatment is invariably responsible for triggering oral changes resulting from the decrease in the patient's immune response. Chemotherapy is one of the most used and effective forms of cancer treatment, however it triggers countless side effects in all organic systems, including in the oral cavity. Among them, mucositis stands out, one of the causes of greatest discomfort for the patient, also responsible for an instability in his quality of life. It is essential that the cancer patient seek a dental surgeon so that there is a prevention, treatment and monitoring of these changes aiming at an improvement in the quality of life before, during and after chemotherapy or any other cancer treatment. Therefore, it is extremely important to determine the main oral changes related to chemotherapy treatment, as well as to assess the prevalence of each change and its toxic effects.

Palabras clave: Quimioterapia; Cambios orales; Cáncer; Efectos tóxicos. 


\section{Introdução}

O desenvolvimento de um tratamento eficaz contra o câncer continua sendo um objetivo determinante da pesquisa biomédica. Apesar dos avanços em vários campos da oncologia, o tratamento do câncer ainda se baseia principalmente na administração de quimioterapia associada ou não a radioterapia e cirurgia (Slapak \& Kufe, 1998)

Nos dias atuais, as neoplasias são a segunda causa de mortes por doença no mundo. Cerca de $70 \%$ dos pacientes doentes terão que fazer quimioterapia no decorrer do tratamento, sendo que, dependendo do tempo, tipo e dosagem dos agentes quimioterápicos, várias complicações severas poderão se desenvolver no paciente. Independente do sítio primário do câncer, cerca de $40 \%$ dos pacientes oncológicos no quais foi realizado tratamento quimioterápico apresentam complicações orais por meio da estomatotoxicidade direta ou indireta, como mucosite, xerostomia e infecções fúngicas ou virais (Martins, Caçador \& Gaeti, 2002).

O câncer de cabeça e pescoço, onde em nível mundial representa $10 \%$ dos tumores malignos, apresenta envolvimento em vários sítios, onde cerca de 40\% dos casos ocorrem na cavidade bucal, 25\% na laringe, 15\% na faringe, 7\% nas glândulas salivares e $13 \%$ nos demais locais. Relata-se mais de oito milhões de casos novos de câncer no mundo, dos quais 212.000 primários de cavidade bucal (Cardoso et al., 2005).

Observasse que o conhecimento sobre o câncer tem avançado bastante e está sendo desenvolvido novas formas de tratamento. Antigamente, o diagnóstico estava associado, invariavelmente, à morte certa. Hoje em dia, com as novas possibilidades de tratamento, observa-se uma sobrevida prolongada e, em muitos casos, a probabilidade de cura. Atualmente entre às formas convencionais de tratamento das neoplasias malignas, destaca-se a cirurgia, a radioterapia, a quimioterapia e a imunoterapia (Souza et al., 2008).

A principal atuação das drogas quimioterápicas é em células tumorais, destruindo-as ou impedindo a sua reprodução. Entretanto, algum dano sobre os tecidos normais é inevitável, particularmente naqueles em que ocorre naturalmente uma rápida divisão celular (cabelos, mucosas, sistema hematopoiético). Assim sendo, muitos desses medicamentos estão relacionados com complicações orais e podem produzir estomatotoxicidade direta ou indiretamente (Rosa, 1997).

Em relação as sequelas e complicações da quimioterapia é possível analisar que na boca é comum o aparecimento de mucosite e algumas outras complicações.

A mucosite oral é desenvolvida após alguns dias do tratamento antineoplásica, associado a mielossupressão, citotoxicidade direta por meio das drogas utilizadas na terapia, supressão imunológica ou hiperatividade. Clinicamente verifica-se inflamação e ulceração da mucosa oral, onde a mesma apresentasse edemaciada, eritematosa e friável, associada a dor, desconforto, disfagia e debilidade sistêmica. Associado a neutropenia que acontece consequência do tratamento, observase o desenvolvimento de infecções por micro-organismos oportunistas como Candida albicans, Herpes Simples Vírus (HSV), citomegalovírus, varicela zoster entre outros. Além disso, também é possível observar hemorragia intra-oral desenvolvida de forma secundária à trombocitopenia pela supressão medular (Franceschini, Jung \& Amante, 2003).

A quimioterapia, onde é aplicada em altas doses afeta a proliferação celular epitelial, onde o resultado é uma atrofia do epitélio e perda da barreira de proteção. A diminuição do mesmo pode levar a uma inflamação dos tecidos por meio da interação com citocinas produzidas no tecido conjuntivo. Onde a associação destes fatores locais, a má higiene oral dos pacientes aumenta a gravidade do quadro clínico, com maior risco de bacteremias (Souza et al., 2008).

Por meio disso a odontologia tem um papel importante nas diferentes fases terapêuticas contra o câncer. É imprescindível o acompanhamento com o paciente antes, durante e após o tratamento. A atuação do dentista é necessária em todas as fases, seja na fase que antecede a cirurgia, onde a avaliação prévia poderá reduzir de forma efetiva complicações por meio de processos infecciosos ou inflamatórios crônicos, de origem bucal, que podem piorar após o tratamento cirúrgico, seja na prevenção das sequelas bucais que ocorrem durante e após o tratamento (Cardoso et el., 2005). 
Resumindo, após análise da literatura especializada, podemos notar que a utilização de quimioterapias é muito eficaz para o tratamento do câncer, porem vários efeitos tóxicos podem desenvolver no paciente. Os principais efeitos colaterais orais da quimioterapia podem ser agrupados em quatro seções principais: mucosite, xerostomia, infecções e neurotoxidade, causando assim um maior desconforto para o paciente. A consulta regular com o dentista é muito importante para diminuição de tais ocorrências assim com a incidência e agravamento da toxidade. O objetivo do tratamento é eliminar ou estabilizar as condições bucais indesejadas assim como minimizar a infecção local e sistêmica, durante e após o tratamento do câncer.

\section{Metodologia}

O presente trabalho se apresenta como um artigo de revisão que pode ser definido como "o resultado de uma investigação tanto teórico-empírica. O que caracteriza este tipo de artigo é que nele se discutem informações já publicadas, portanto oriundas de dados secundários" (Zanella, 2011, p. 88), quanto a abordagem do artigo pode-se afirmar que é qualitativo, pois o foco é descrever e analisar os fenômenos abordados (Zanella, 2011).

\section{Resultados}

Uma grande quantidade de alterações bucais pode desenvolver-se em pacientes submetidos a tratamentos com agentes quimioterápicos. Tendo por sua vez a mucosite oral e a xerostomia como as principais alterações presentes (Araujo et al., 2015).

A grande maioria das drogas que são utilizadas na quimioterapia antineoplásica afeta o mecanismo celular, onde a danos na função e na proliferação celular. Porém não atuam exclusivamente sobre as células tumorais, atingindo também estruturas normais, principalmente as que se renovam constantemente. Efeitos agudos ocorrem com o tratamento quimioterapia e afeta os tecidos com uma alta taxa renovação de células, como o revestimento da boca. Efeitos tardios aparecem depois do fim do tratamento, também ocorre com mais frequência em órgãos com especificidade celular, como músculo e osso (Brasil, 2005; Faza \& Brum, 2018).

\subsection{Mucosite}

Podemos definir a mucosite oral através de inflamação por relação toxica com exposição as drogas do tratamento quimioterápico. Esta relação tóxica pode ser definida pela capacidade das drogas em diminuir e inibir a divisão celular epitelial na camada basal da boca. Observa-se também que a rápida renovação dessas células garante uma renovação no epitélio que descama em função do atrito constante presente na boca (Santos et al., 2006).

Inicialmente a primeira manifestação em cavidade bucal é uma coloração esbranquiçada pois não a descamação suficiente de ceratina. Em seguida a uma perda da camada com reposição pela mucosa atrófica, no qual a mesma é edematosa, eritematosa e friável. Observa-se o aparecimento de ulceras com a formação de uma membrana superficial fibrinopurulenta, amarelada e removível. Há também o aparecimento de dor, queimação e desconforto significativos que podem ficar mais evidentes durante a alimentação e higienização bucal (Neville et al., 2002).

Quanto sua evolução a mucosite é temporária, entretanto apresentam controversas. Pacientes em tratamento quimioterápico, a manifestação pode vim a ocorrer em até 24 horas ou dentro de três a dez dias de tratamento. A avaliação clínica a mucosite bucal se caracteriza por eritema e edema, sensação de queimação, sensibilidade aumentada a alimentos quentes e condimentos, onde áreas eritematosas tem o desenvolvimento de placas brancas, elevadas descamativas bem como úlceras dolorosas que podem desencadear infecções secundárias (Santos et al., 2006; Martins et al., 2002). 
Segundo a OMS, podemos classificar a mucosite com o grau de gravidade. Onde podemos ver no grau I esbranquiçamento da mucosa bucal, principalmente na mucosa jugal. O grau II é o início do desenvolvimento de úlceras pequenas, dolorosas. Já o grau III apresenta as úlceras maiores, já com dificuldades na alimentação e no grau IV, a uma generalização da doença na boca, observando a dificuldade do paciente se alimentar por via oral e levando à necessidade de internação do mesmo. O grau exato da mucosite é determinado pela combinação do exame clínico sobre a dor, estado nutricional e por sua reação local na mucosa oral (Jham e Freire, 2006).

Uma boa higiene oral pode ajudar no controle da mucosite, onde a uma diminuição do número de patógenos orais potenciais. Bochechos com hidróxido de alumínio e magnésio (sabor não ácido) com gluconato de clorexidina a 0,12\%, antiinflamatórios, anestésicos, laser terapia de baixa potência, glutamina e bochechos com chá de camomila tem sido relatado na prevenção e controle da mucosite oral (Labbate, Lehn \& Denardin, 2003; Sandoval et al., 2003; Savarese et al., 2003).

\subsection{Xerostomia}

A xerostomia está associada a uma sensação subjetiva de secura na boca, e está frequentemente associada à hipofunção da glândula salivar. A xerostomia vem acontecer porque os pacientes mostram uma concentração dos agentes quimioterápicos na saliva, onde tem uma exposição da mucosa oral à toxicidade. A queixa de secura da boca e espessamento do fluxo salivar evidenciam a xerostomia. Ardência na mucosa bucal, ressecamento dos lábios, comissuras labiais fissuradas, alteração da superfície da língua bem como modificação no paladar podem ser sintomas referidos (Nevill et al., 2002; Dib et al., 2003).

A xerostomia deixa o meio bucal desprotegido e propenso a infecções secundárias, além de tornar a saliva espessa e pegajosa, causando mudanças nos hábitos alimentares dos pacientes que passam a ingerir mais alimentos líquidos e pastosos pouco espessos (Epstein \& Schubert, 2002).

Para realização do tratamento e proteção pode ser utilizado colutórios no quais tem ação direta na gengiva e na mucosa bucal bem como ação antibacteriano.Também pode ser feito com solução salina normal para umedecer a mucosa, bem como remoção de detritos e estimular a função das glândulas salivares. Alguns medicação são encontradas nas formas de pulverização, géis, líquidos para bochecho e pastilhas disponíveis sem a necessidade de receitas médicas, métodos conhecidos como estimulantes tópicos. Já de forma mais avançada, caso o paciente não tenha melhora com tais tratamentos, pode ser utilizado medicamentos (sialogogo), para estimulação da saliva através do sistema nervoso parassimpático. Os mais conhecidos são a pilocarpina e a cevimelina. A saliva artificial promove um alívio somente no momento, porem se não for observado melhoria com medicamentos, devemos fazer uso continuo da mesma. Lábios secos ou rachados podem ser lubrificados com agentes à base de lanolina e hidratantes não perfumados para a pele (Dalmagro et al., 2015).

\subsection{Infecções Oportunistas}

\subsubsection{Infecção Fúngica}

$\mathrm{O}$ aparecimento de infecção fúngica bem como a colonização superficial por Candida albicans, ocorre com frequência em pacientes submetidos à quimioterapia, devido a alterações da competição da flora bucal, xerostomia e imunossupressão que promovem sua proliferação excessiva. As infecções por Candida podem assumir as formas eritematosa, hiperplástica, invasiva e pseudomembranosa. Esta última é a mais comum, caracterizada pela colonização maciça da superfície, exibindo massas elevadas, brancas e semelhantes a coalhos de microrganismos. A candidíase eritematosa é comum no dorso da língua e consiste na perda focal das papilas filiformes. Em invasões mais profundas nos pacientes com imunossupressão significativa ocorrem lesões distintas, firmes, quase coriáceas e branco-amareladas com eritema marginal que causam um elevado risco de 
disseminação sistêmica. Infecções das comissuras labiais apresentam-se como rachaduras, dor e graus variáveis de eritema (Martins et al., 2002).

\subsubsection{Infecções Virais}

Em pacientes submetidos à quimioterapia é comum infecções por vírus do grupo herpes. Infecções por HSV, VZV, CMV, HHV-6 e EBV ocorrem por reativação de vírus latentes. Outro vírus pode causar lesões bucais nestes pacientes: coxsackievírus (mão-pé-boca) (Martins et al., 2002).

\subsubsection{Infecções Bacterianas}

As infecções bacterianas são causadas pelo crescimento excessivo de microrganismos patogênicos que invadem a boca. Ao aderir à mucosa, esses microrganismos se espalham formando infecções, como abcessos, ou causa inflamação generalizada, feridas e inchaço, tendo assim uma porta de entrada para outros microrganismos oportunistas. Desta forma podem ocorrer aquisições de microrganismos não bucais e aumento de infecções bacterianas em pacientes imunossuprimidos (dependendo da duração e intensidade da imunossupressão, principalmente em caso de neutropenia). O uso de antibióticos tem alterado a microflora bucal. A mucosite e ruptura mecânica da mucosa bucal podem ser agravadas devido à facilidade de invasão de microrganismos (Martins, Domingues \& Sêneda, 2005; Costa et al., 2019).

\subsection{Neurotoxicidade}

A neurotoxicidade está associada ao envolvimento de substâncias tóxicas naturais ou artificiais, levando a alteração do sistema nervoso associado aos danosa tal tecido, podendo assim levar a morte de alguns neurônios. Clinicamente uma das principais características seria um quadro de dor inespecífica, tendo relação com drogas quimioterápicos, onde os sintomas podem ser imediatos ou retardados. Os derivados de alcalóides da vinca e, indiretamente causam parestesia na boca, hipersensibilidade dentária e disfunções temporomandibulares causando dor ao morder e dor miofascial. A dor é persistente, contínua e é parecida com dores de dente, porém nenhuma alteração dentária ou na mucosa é visualizada. Para o seu controle, recomenda-se a utilização de analgésicos de efeito sistêmico (Jensen et al., 2003).

\section{Discussão}

Araújo et al. (2015) ressaltaram que alterações mais frequentes com relação a quimioterapia é a xerostomia e a mucosite oral, onde a maioria dos pacientes por eles avaliados apresentaram tais complicações. Faza et al. (2018), dividiu mulheres e homens para realizar uma avaliação enquanto os mesmos estavam sob tratamento quimioterápico. Os pesquisadores observaram que em pacientes homens a alteração com maior prevalência foi a xerostomia e a com menor prevalência foi a mucosite. Já entre as pacientes mulheres a xerostomia foi a mais prevalente e as lesões herpéticas a com menor prevalência. Visto que de forma independente (sexo ou idade), a alteração mais comum foi a xerostomia, e a com menor incidência foi a herpes.

Moura et al. (2006) destacam de que mucosite oral é causada pela toxidade dos agentes usados na quimioterapia, no qual diminui ou inibe a divisão celular na camada basal, onde foi notado uma descamação rápida do epitélio pelo fato da grande quantidade de atrito sobre o local. Já Castro et al., em 2002, ratificam que a mucosite pode apresentar diferentes épocas para aparecimento. Todos os autores foram unanimes em descrever que o tempo de desenvolvimento é de 24 horas ou de 3 a 10 dias durante o tratamento.

Neville et al. (2004) constataram que a mucosite apresenta-se primeiramente com uma coloração esbranquiçada pela dificuldade de descamação do tecido, onde logo após a perda deste tecido esbranquiçado notaremos ulceras coberta por uma 
membrana amarelada e removível com dor, queimação e desconforto. Oliveira et. al. descreveram as formas na qual a mucosite é dividida segundo a OMS, onde iremos observar a mesma sendo dividida em 4 (quatro) parâmetros: grau I forma esbranquiçada, grau II início de ulceras, grau III ulceras maiores causando dificuldade de alimentar, grau IV generalização da doença na boca tendo que levar o mesmo para o hospital para realizar alimentação. Iremos definir seu grau pelo exame clinico sobre a dor do paciente, estado nutricional e reação local sobre a mucosa.

Labbate et al. (2003) analisaram que a clorexidina a 0,12\% pode levar uma diminuição dos efeitos da mucosite. Assim como Sandoval el. al., mostraram melhorias com a utilização do laser de baixa potência, onde a doença não é eliminada porem melhora os sintomas da mesma. Já Savarese et. al. (2003) observaram que a suplementação com glutamina pode diminuir a incidência ou gravidade da mucosite, objetivando sempre a melhoria da qualidade de vida do paciente durante a quimioterapia.

Dib et. al. (2002) e Neville et al. (2004), associaram a xerostomia como uma sensação de boca seca no qual está relacionada a uma perda de função da glândula salivar. Nota-se uma grade quantidade de agentes quimioterápicos na saliva, na qual a mucosa oral fica exposta a tal toxidade. Os autores notaram que a principal queixa foi secura na boca e espessamento do fluxo salivar, no qual tal alteração vem a causar ardência na mucosa bucal, lábios ressecados, fissuras em comissuras labiais, superfície lingual alterada causando mudanças no paladar. Epstein et al., em 1999 referenciaram que a xerostomia deixa o meio bucal sem proteção deixando o mesmo favorável para aparecimento de infecções secundarias, proporcionando mudanças nos hábitos alimentares no qual tem maior ingestão de líquidos e pastosos pouco espessos.

Dalmagro et al. (2015) ressaltaram os possíveis tratamentos para auxiliar a qualidade de vida do paciente, onde iremos utilizar de colutorios para proteção da gengiva e mucosa bucal por seu efeito é antibacteriano, bem como estimulantes na produção da saliva, como goma de mascar, pastilhas, líquidos para bochechos. Caso não for observado resultado iremos entrar com ações medicamentosas como sialogogos e saliva artificial.

Castro et al. (2002) observaram o aparecimento de infecção fúngica causada pela Candida Albicans. A mesma é encontrada pela alteração da flora bucal, onde são apresentadas em 4 (quatro) formas: eritematosa, hiperplástica, invasiva e pseudomembranosa. Os autores citam como a mais comum a pseudomembranosa apresentando massas elevadas brancas de fácil remoção, pode ser conhecida também como sapinho. Ainda destaca-se a quelite angular, sendo uma infecção em comissura labial onde apresenta rachaduras, dor e eritema. Os autores ainda destacam algumas infecções virais como herpes, HSV, VZV, CMV, HHV-6 E EBV onde irão ocorrer através da ativação de vírus latentes.

Martins et al. (2005) e Costa et al. (2019) destacaram que pacientes submetidos a quimioterapia também apresentaram infecções bacterianas relacionadas a cavidade bucal, no qual as mesmas são responsáveis por abcessos, inflamações generalizadas, feridas e inchaço. Tais bactérias já estão presentes no meio bucal e com um desequilíbrio da microflora bucal se manifestam tais alterações formando uma porta de entrada para outros microrganismos oportunistas.

Jensen et al. (2003) referenciaram a neurotoxicidade como sendo um envolvimento com substancias toxicas naturais ou artificiais (neurotoxinas), onde a mesma ataca o sistema nervoso causando dano a tal tecido. Relatou-se a dor como o principal sintoma, podendo aparecer de imediato ou retardado, sendo ela persistente, continua semelhante a dor de dente porem sem alterações visíveis. Para melhoria da dor recomendasse uso de analgésicos de efeito sistêmico.

\section{Considerações Finais}

Considerando a quimioterapia como um dos principais métodos de combate ao câncer é imprescindível que o cirurgião dentista conheça as alterações bucais provenientes de tal ação. A literatura especializada destaca inúmeras sequelas associadas a quimioterapia, mas entre elas destacam-se a mucosite e a xerostomia. Também é notório o papel do dentista na melhorara da qualidade de vida do paciente durante o processo de quimioterapia através de tratamentos coadjuvantes para tais alterações em cavidade oral. 
Os estudos aqui apresentados apresentaram mostraram que há relevância da atuação do profissional cirurgião dentista na recuperação das sequelas decorrentes de quimioterapia, entretanto se faz necessário análise clínica sobre tais casos, para aprofundar o conhecimento sobre a qualidade de vida que o cirurgião dentista pode trazer à esta população.

Por fim, entende-se que a alteração da flora, a toxidade e a pouca saliva, que são alguns efeitos da quimioterapia e radioterapia, podem causar desconforto ou problemas na saúde bucal, deste modo, se recomenda estudos que rastreiem o início destes sintomas, e já comecem um tratamento precoce com o objetivo de evitar infecções bucais, para isso pode-se pensar em dois grupos, sendo um de controle, e um grupo tratado de modo preventivo contra os efeitos da quimioterapia nas funções salivares.

\section{Referências}

Araujo, T. L. C. et. al. (2015). Manifestações bucais em pacientes submetidos a tratamento quimioterápico. Revista cubana de estomatologia. 52(4): 16-22.

Caponero, R., Montarroyos, E., \& Tahamtani, S. M. M. (2016). Post-chemotherapy neuropathy. Revista Dor, 17, $56-58$.

Cardoso, M. F. A., Novikoff, S., Tresso, A., Segreto, R. A. \& Cervantes O. (2005). Prevenção e controle das seqüelasbucais em pacientes irradiados por tumores de cabeça e pescoço. Radiol Bras. 38(2): 107-115. http://www.scielo.br/scielo.php?script=sci_arttext\&pid=S010039842005000200006\&lng=en. https://doi.org/10.1590/S0100-39842005000200006.

Costa, R. G., Ponte, I. P. F. et. al. (2019). Manifestações bucais mediante a quimioterapia em pacientes oncológicos, unifacig seminário cientifico, 8.

Dalmagro, M. F. et al. (2015). Xerostomia: Desenvolvimento de uma bala com potencial sialogogo. Saúde e Desenvolvimento Humano 3. 2:35-44.

Dib, L. L., \& Curi, M. M. (2002). Complicações orais na Oncologia: atuação odontológica na Oncologia. In: Kowalski L.P. et al. Manual de condutas diagnósticas e terapêuticas em Oncologia. (2a ed.), Âmbito Ed, 199-205.

Dib, L. L., Gonçalves, R. C. C., Kowalski L. P. \& Salvajoli, J. V. (2000). Abordagem multidisciplinar das complicaçõesorais da radioterapia. Rev APCD. 2000, 54:391-6.

Epstein, J. B. \& Schubert, M. M. (1999). Oral mucositis in myelosuppressive Cancer therapy. Oral Surg Oral Med Oral Pathol Oral Radiol Endod, 88 (3):273-27.

Franceschini, C., Jung, J. E. \& Amante, C. J. (2003). Mucosite oral pós-quimioterapia em pacientes submetidos à supressão de medula óssea. Rev Bras Patol Oral, 2(1):40-43.

Instituto Nacional de Câncer (Brasil). (2005). Câncer: perguntas e respostas. Brasília, 2005. Disponível em: http://www.inca.gov.br/. Acesso em: 20 set. 2019 .

Jensen, S. B., Pedersen, A. M., Reibel, J. \& Nauntofte, B. (2003). Xerostomia and hypofunction of the salivary glands in cancer therapy. Support Care Cancer. 11:207-25.

Jham, B.C., \& Freire, A. R. S. (2006). Complicações bucais da radioterapia em cabeça e pescoço. Revista Brasileira de Otorrinolaringologia, Set./Out. 2006, $72(5)$.

Faza, J. \& Brum, S. C. B. (2018). A influência da quimioterapia na saúde bucal. Revista Pró- univerSUS. 09(2):81-89.

Labbate, R., Lehn, C. N. \& Denardin, O. V. P. (2003). Efeito da clorexidina na mucosite induzida por radioterapia em câncer de cabeça e pescoço. Rev Bras Otorrinolaringol. 69:349-54.

Martins, A. C. M., Caçador, N. P. \& Gaeti, W. P. (2002). Complicações bucais da quimioterapia antineoplásica. Acta Scientiarum, 24(3):663-670.

Martins, C. R. F. et al. (2002). Atenção Odontológica aos pacientes oncológicos antes, durante e depois tratamento antineoplásico. Rev. odontol. UNICID, 14(1):1-7. http://bases.bireme.br/cgi-bin/wxislind.exe/iah/online/?IsisScript=iah/iah.xis\&src=google\&base=LILACS\&lang=p\&nextAction=1 nk\&exprSearch=329284\&indexSearch=ID.

Martins, M., Domingues, A. T., \& Sêneda, L. M. (2005). Suporte odontológico ao paciente oncológico: prevenção, dớd tratamento e reabilitação das sequelas bucais. Prática Hospitalar, (41).

Neville, B. W., Damm, D. D., Allen, C. M. \& Bouquot, J. E. (2004). Patologia Oral e Maxilofacial. Tradução: Editora Guanabara Koogan, (2a ed.), Editora Guanabara Koogan.

Rosa, L. N. Atenção estomatológica aos pacientes pediátricos oncológicos. (1997). RGO 45(2): 111-4.

Sandoval, R. L. et al. (2003). Management of chemo- and radiotherapy induced oral mucositis with low energy laser: initial results of A.C. Camargo Hospital. J. Appl. Oral Sci. 11:337-41.

Santos, A. C. M. et al. (2006). Complicações bucais notratamento radioterápico. Medcenter. 
Research, Society and Development, v. 10, n. 6, e59510616562, 2021

(CC BY 4.0) | ISSN 2525-3409 | DOI: http://dx.doi.org/10.33448/rsd-v10i6.16562

Savarese, D. M. F. et al. (2003). Prevention of chemotherapy and radiation toxicity with glutamine. Cancer Treat Rev., 29:501-3.

Slapak, C. A. \& Kufe, D. W. (1998). Princípios do tratamento do câncer. In: Harrison-Principles of Internal Medicine. (14):596-11.

Sousa, G. R. de. et. al. Lasers em baixa intensidade no tratamento de mucosites em paciente submetido à quimioterapia. Relato de caso. Odotologia, Ciência e Saúde - Revista do CROMG, 10(1).

Zanella, L. C. H. (2011). Metodologia de pesquisa. UFSC. 